\title{
Endoscopic management of Barrett's esophagus: European Society of Gastrointestinal Endoscopy (ESGE) Position Statement
}

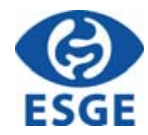

Authors

Bas Weusten ${ }^{1,2}$, Raf Bisschops ${ }^{3}$, Emanuel Coron ${ }^{4}$, Mário DinisRibeiro $^{5}$, Jean-Marc Dumonceau6 ${ }^{6}$, José-Miguel Esteban7, Cesare Hassan $^{8}$, Oliver Pech ${ }^{9}$, Alessandro Repici ${ }^{10}$, Jacques Bergman², Massimiliano di Pietro ${ }^{11}$

\section{Institutions}

1 Department of Gastroenterology and Hepatology, St. Antonius Hospital, Nieuwegein, The Netherlands

2 Department of Gastroenterology and Hepatology, Academic Medical Center, Amsterdam, The Netherlands

3 Department of Gastroenterology, University Hospital Leuven, Leuven, Belgium

4 Institut des Maladies de l'Appareil Digestif, CHU and University, Nantes, France

5 Department of Gastroenterology, Portuguese Oncology Institute-Porto, Porto, Portugal

6 Gedyt Endoscopy Center, Buenos Aires, Argentina

7 Department of Endoscopy, Hospital Clinico San Carlos, Madrid, Spain

8 Department of Gastroenterology, Nuovo Regina Margherita Hospital, Rome, Italy

9 Department of Gastroenterology and Interventional Endoscopy, St. John of God Hospital, Regensburg, Germany

10 Department of Gastroenterology, Humanitas Research Hospital, Humanitas University, Milano, Italy

11 MRC Cancer Unit, University of Cambridge, Cambridge, United Kingdom

Bibliography

DOI http://dx.doi.org/10.1055/s-0042-122140

Published online: 25.1.2017 | Endoscopy 2017; 49: 191-198

(c) Georg Thieme Verlag KG Stuttgart · New York

ISSN 0013-726X

Corresponding author

Bas L. A. M. Weusten, MD, PhD, Department of Gastroenterology and Hepatology, St. Antonius Hospital Nieuwegein, Koekoekslaan 1, 3435CM Nieuwegein, The Netherlands

Fax: +31-88-3205699

b.weusten@antoniusziekenhuis.nl

\section{ABSTRACT}

Current practices for the management of Barrett's esophagus (BE) vary across Europe, as several national European guidelines exist. This Position Statement from the European Society of Gastrointestinal Endoscopy (ESGE) is an attempt to homogenize recommendations and, hence, patient management according to the best scien- tific evidence and other considerations (e.g. health policy). A Working Group developed consensus statements, using the existing national guidelines as a starting point and considering new evidence in the literature. The Position Statement wishes to contribute to a more cost-effective approach to the care of patients with BE by reducing the number of surveillance endoscopies for patients with a low risk of malignant progression and centralizing care in expert centers for those with high progression rates.

\section{MAIN STATEMENTS}

MS1 The diagnosis of BE is made if the distal esophagus is lined with columnar epithelium with a minimum length of $1 \mathrm{~cm}$ (tongues or circular) containing specialized intestinal metaplasia at histopathological examination.

MS2 The ESGE recommends varying surveillance intervals for different BE lengths. For patients with an irregular Z-line/columnarlined esophagus of $<1 \mathrm{~cm}$, no routine biopsies or endoscopic surveillance is advised. For $B E \geq 1 \mathrm{~cm}$ and $<3 \mathrm{~cm}$, BE surveillance should be repeated every 5 years. For $B E \geq 3 \mathrm{~cm}$ and $<10 \mathrm{~cm}$, the interval for endoscopic surveillance should be 3 years. Patients with $B E$ with a maximum extent $\geq 10 \mathrm{~cm}$ should be referred to a $B E$ expert center for surveillance endoscopies. Patients with limited life expectancy and advanced age should be discharged from endoscopic surveillance.

MS3 The diagnosis of any degree of dysplasia (including "indefinite for dysplasia") in BE requires confirmation by an expert gastrointestinal pathologist.

MS4 Patients with visible lesions in BE diagnosed as dysplasia or early cancer should be referred to a BE expert center. All visible abnormalities, regardless of the degree of dysplasia, should be removed by means of endoscopic resection techniques in order to obtain optimal histopathological staging

MS5 All patients with a $B E \geq 10 \mathrm{~cm}$, a confirmed diagnosis of low grade dysplasia, high grade dysplasia (HGD), or early cancer should be referred to a BE expert center for surveillance and/or treatment. $\mathrm{BE}$ expert centers should meet the following criteria: annual case load of $\geq 10$ new patients undergoing endoscopic treatment for HGD or early carcinoma per BE expert endoscopist; endoscopic and histological care provided by endoscopists and pathologists who have followed additional training; at least 30 supervised endoscopic resection and 30 endoscopic ablation procedures to acquire competence in technical skills, management pathways, and complications; multidisciplinary meetings with gastroenterologists, surgeons, oncologists, and pathologists to discuss patients with Barrett's neoplasia; access to experienced esophageal surgery; and all $\mathrm{BE}$ patients registered prospectively in a database.

Appendix e 1 - e4

Online content viewable at: https://www.thieme-connect.com/

DOI/DOI?10.1055/s-0042-122140 


\begin{tabular}{|c|c|}
\hline \multicolumn{2}{|c|}{ ABBREVIATIONS } \\
\hline BE & Barrett's esophagus \\
\hline BSG & British Society of Gastroenterology \\
\hline DGVS & $\begin{array}{l}\text { Deutsche Gesellschaft für Gastroenterologie, } \\
\text { Verdauungs- und Stoffwechselkrankheiten } \\
\text { (German Society of Gastroenterology, Digestive } \\
\text { and Metabolic Diseases) }\end{array}$ \\
\hline EAC & esophageal adenocarcinoma \\
\hline EMR & endoscopic mucosal resection \\
\hline ESD & endoscopic submucosal dissection \\
\hline ESGE & European Society of Gastrointestinal Endoscopy \\
\hline GERD & gastroesophageal reflux disease \\
\hline GI & gastrointestinal \\
\hline HGD & high grade dysplasia \\
\hline IM & intestinal metaplasia \\
\hline LGD & low grade dysplasia \\
\hline RFA & radiofrequency ablation \\
\hline SIED & $\begin{array}{l}\text { La Società Italiana di Endoscopia Digestiva } \\
\text { (Italian Society of Digestive Endoscopy) }\end{array}$ \\
\hline SKMS & $\begin{array}{l}\text { Stichting Kwaliteitsgelden Medisch Specialisten } \\
\text { (Dutch Quality Fund for Medical Specialists) }\end{array}$ \\
\hline
\end{tabular}

\section{Introduction}

Barrett's esophagus (BE) is a premalignant condition predisposing to esophageal adenocarcinoma (EAC). Although the risk of cancer progression is low (estimated at about $0.3 \%$ per year [1]), in most countries patients with BE are managed with endoscopic surveillance at regular intervals. However, current practices for the management of BE and EAC vary across Europe, as several national European guidelines exist. The current Position Statement from the European Society of Gastrointestinal Endoscopy (ESGE) is an attempt to homogenize recommendations and, hence, patient management according to the best scientific evidence as well as other considerations (e.g. health policy). The aim of this document, therefore, is to deliver a very practical guide, in the form of a Position Statement, even when supporting evidence is weak [2].

A secondary aim of the current Position Statement is to contribute to a more cost-effective approach to the care of patients with $\mathrm{BE}$, through reduction of the number of surveillance endoscopies for patients with a low risk of malignant transformation, and centralization of care for those with higher progression rates. This was felt necessary because, although several recent reports indicate that the outcome of BE-associated EAC is improved with endoscopic surveillance of $B E[3,4]$, the annual incidence of EAC among patients with BE is relatively low. The burden on gastrointestinal (GI) endoscopy facilities and health care resources might therefore be reduced.

In developing this Statement, we focused on issues that were directly relevant to endoscopy practice. Hence, other issues, such as chemoprevention for progression of BE or the use of biomarkers for prediction of progression in BE, are not part of this Position Statement.

\section{Methodology}

Recently, several national guidelines have been issued in Europe for the management of BE, either in international scientific journals or as consensus statements distributed locally by national societies. These existing guidelines served as the starting point for the current Position Statement in order to take advantage of the discussions of the scientific literature performed by the respective national BE guideline committees.

In order to retrieve as many national European guidelines as possible, an inquiry was sent to all national gastrointestinal endoscopy society members of the ESGE. Questions in the survey were:

1. Has your national society ever produced their own national guideline on BE? If so, when was it written or published?

2. Is there a particular guideline on BE that your society recommends endoscopists follow?

3. Which currently available guideline on BE do you think is mostly used by endoscopists in your country?

4. Are you currently considering writing a national guideline on $\mathrm{BE}$, or are you planning to revise your current guideline?

The results of this inquiry are summarized in Supplementary Material 1.

Using the results of this inquiry, four recent national guidelines were selected based on year of publication and robustness of methodology: the British Society of Gastroenterology (BSG) guidelines on the diagnosis and management of Barrett's esophagus [5], the German Society of Gastroenterology, Digestive and Metabolic Diseases (DGVS) guideline on gastroesophageal reflux disease (GERD), which includes recommendations for BE [6], the Italian Society of Digestive Endoscopy (SIED) consensus meeting on the diagnosis and management of BE (see Supplementary Material 2), and the Dutch Guideline on BE funded by the Dutch Quality Fund for Medical Specialists (SKMS; http://www.mdl.nl/richtlijnen2?noCache=214;1484584659.

See Supplementary Material 3, in Dutch only).

Members of the Working Group on the ESGE Position Statement on the endoscopic management of $\mathrm{BE}$ were selected based on their contribution to the included national guidelines, complemented by recognized experts on BE from other European countries. All Working Group members are listed as contributing authors on this paper.

A list of topics to be covered by the current Position Statement was derived from the existing guidelines, and agreed on during a teleconference of the Working Group members (see Supplementary Material 4). Subsequently, all relevant statements of the four selected national guidelines were sorted into a table, according to this list of topics. All Working Group members where then asked to complete three additional columns containing the following questions:

1. Are all recommendations from the four merging guidelines in agreement (Yes/No, explain)?

2. If Yes, do you personally agree (Yes/No, explain)?

3. Are you aware of any new studies relevant for this issue (Yes/ No, explain)? 
In order to cover the gap between the time period covered by the literature searches of the selected national guidelines and the ESGE Position Statement, a Medline search was performed through PubMed for the period January 2013 - November 2015.

During a consensus meeting, the statements of the existing national guidelines were discussed. In the case of discrepancy between recommendations of the national guidelines, new statements were generated based on a consensus agreement among the Working Group members, supported by new literature if available. Comments were added to the statements, if necessary, in order to: mention or discuss additional evidence arising from new literature; clarify the statement in case of partial agreement or disagreement among the four national guidelines; highlight additional important insights of the working group members; or a combination thereof. The manuscript was then sent to the ESGE Governing Board, member societies, and individual members for comment.

As the current ESGE Position Statement on the endoscopic management of BE was largely formed by merging the four existing national guidelines, the reader is referred to these publications for full lists of references.

\section{Statements}

Each statement is followed by information on:

- Extent of agreement between the four constituent guidelines

- Availability of new evidence

- Whether there is consensus between the Working Group members on the current statement.

This may be followed by additional Comments, as described above in the Methodology section.

\section{STATEMENT 1}

The diagnosis of $\mathrm{BE}$ is made if the distal esophagus is lined with columnar epithelium with a minimum length of $1 \mathrm{~cm}$ (tongues or circular) containing specialized intestinal metaplasia at histopathological examination.

- Partial agreement between merged guidelines

- No new evidence available on this statement

- Consensus on current statement between Working Group members

\section{Comments}

In patients with columnar epithelium extending less than $1 \mathrm{~cm}$ above the upper end of the gastric folds (tongues or circular), obtaining random biopsies (i. e. biopsies from columnar epithelium in the absence of a visible abnormality) is not recommended. Targeted biopsies from this region should only be obtained in cases where a visible abnormality is detected. Endoscopic surveillance of patients with these short segments of columnarlined esophagus (tongues or circular columnar epithelium ex- tending less than $1 \mathrm{~cm}$ above the gastric folds) is not recommended, irrespective of presence of intestinal metaplasia (IM).

For $B E \geq 1 \mathrm{~cm}, I M$ is a prerequisite to justify surveillance. In cases where random biopsies are obtained according to guidelines (see Statement 6 below), absence of IM more likely reflects a misinterpretation of a hiatal hernia ( $\mathbf{F i g . 1 )}$ than actual sampling error. For larger segments of BE, absence of IM (provided that random biopsies are obtained according to guidelines) is rare, and the management of these cases does not justify detailed instructions by guidelines.

\section{STATEMENT 2}

Endoscopic screening for BE is not recommended. However, screening can be considered in patients with longstanding GERD symptoms (i.e. $>5$ years) and multiple risk factors (age $\geq 50$ years, white race, male sex, obesity, first-degree relative with $\mathrm{BE}$ or $\mathrm{EAC}$.)

- Agreement between merged guidelines

- No new evidence available on this statement

- Consensus on current statement between Working Group members

\section{STATEMENT 3}

Endoscopic surveillance of BE is recommended.

- Agreement between merged guidelines

- New evidence available on this statement

- Consensus on current statement between Working Group members

\section{Comments}

Currently, randomized controlled trials on surveillance in patients with BE are lacking. However, studies in patients with $\mathrm{BE}$ suggest that adequate endoscopic surveillance correlates with detection of cancer at an earlier stage, and with improved survival from EAC $[3,4]$.

\section{STATEMENT 4}

High definition endoscopy (endoscope, processor, and screen) is recommended for endoscopic surveillance of BE. Routine use of chromoendoscopy, optical chromoendoscopy, autofluorescence endoscopy, or confocal laser endomicroscopy is not advised.

- Agreement between merged guidelines

- No new evidence available on this statement

- Consensus on current statement between Working Group members 


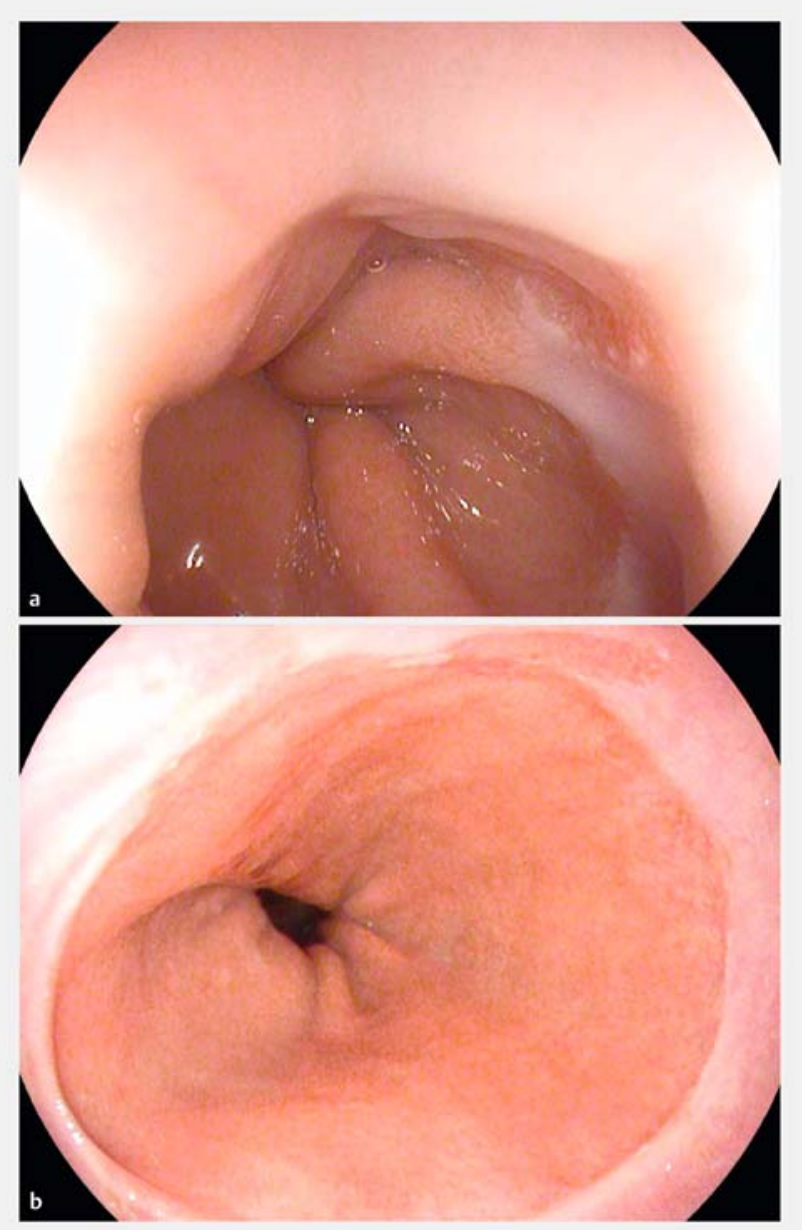

- Fig. 1 Example of a patient with a small hiatal hernia. a The esophagogastric junction in desufflation. The squamocolumnar junction coincides with the location of the top of the gastric folds. b The esophagus and hiatal hernia are overinflated leading to the misinterpretation of the hiatal hernia as circular Barrett's epithelium.

\section{Comments}

For the detection of dysplasia in BE, currently available data do not provide sufficient proof of additional value from the abovementioned advanced imaging techniques over high definition white-light endoscopy. Despite the lack of solid proof, optical chromoendoscopy techniques (narrow-band imaging, flexible spectral imaging color enhancement, I-SCAN) are nowadays widely available and do not impose additional costs; they are used by many experts for the detection and characterization of lesions in BE. Therefore, in high volume centers, the use of advanced imaging modalities can be advantageous during the work-up of patients with early neoplasia to delineate the margins of the lesions and inform endoscopic therapy [7].

\section{STATEMENT 5}

Endoscopy reports of patients with BE should include:

$i$. the extent of BE using the Prague criteria (circumferential extent $[C]$, maximum extent $[M]$ ), and any separate islands proximal to the maximal extent;

ii. a description of location (in $\mathrm{cm}$ from the incisors and clockwise orientation) of any visible abnormality within the Barrett's epithelium, in addition to lesion size ( $\mathrm{mm}$ ) and macroscopic appearance using the Paris classification;

iii. the presence or absence of erosive esophagitis using the Los Angeles classification;

iv. the location of biopsies taken from the Barrett's segment (number of biopsies and location in $\mathrm{cm}$ from the incisors);

v. appropriate photo documentation of the landmarks and of all visible Barrett's epithelium, as well as any visible lesions.

- Agreement between merged guidelines

- No new evidence available on this statement

- Consensus on current statement between Working Group members

\section{Comments}

BE surveillance endoscopy should ideally be performed within specifically allocated time slots, preferably in sedated patients. Before inspection of the BE for any visible lesions, the esophagus should be properly cleaned from mucus by rinsing. Careful attention should be paid to inspection of the cardia, using a retroflexed position ( $\vee$ Video $\mathbf{1}$ ).
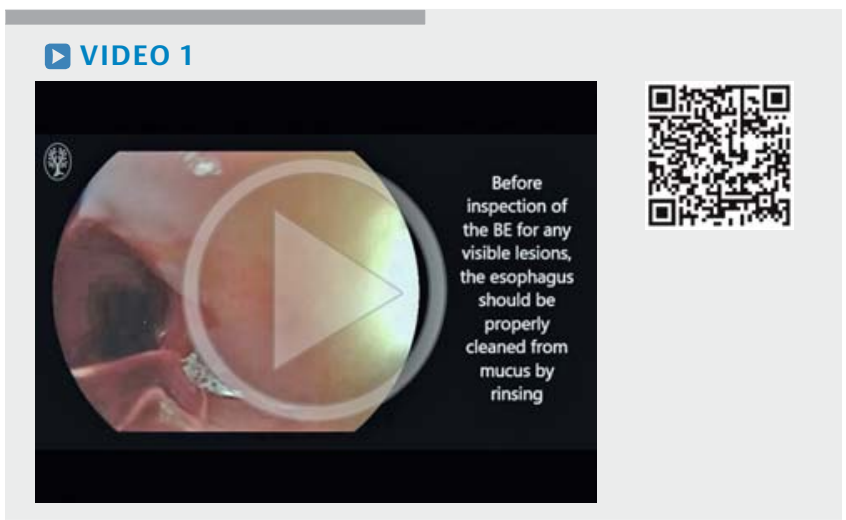

- Video 1: Example of surveillance endoscopy for Barrett's esophagus. The various steps of an appropriate surveillance endoscopy are illustrated, such as cleaning the esophagus to remove mucus, and inspection of the cardia using a retroflexed endoscope position.

Online content viewable at: https://www.thieme-connect.com/ DOI/DOI?10.1055/s-0042-122140 


\section{STATEMENT 6}

Biopsy samples should be taken from all visible mucosal abnormalities. In addition, random 4-quadrant biopsies should be collected every $2 \mathrm{~cm}$ within the Barrett's segment, starting from the upper end of the gastric folds. Biopsies from each level should be collected in and presented to the pathologist in a separate container.

- Agreement between merged guidelines

- No new evidence available on this statement

- Consensus on current statement between Working Group members

\section{STATEMENT 7}

Surveillance intervals for nondysplastic BE should be stratified according to the length of the Barrett's segment. i. Irregular Z-line/columnar-lined esophagus $<1 \mathrm{~cm}$ : no endoscopic surveillance

ii. Maximum extent of $\mathrm{BE} \geq 1 \mathrm{~cm}$, and $<3 \mathrm{~cm}$ : 5 years iii. Maximum extent of $B E \geq 3 \mathrm{~cm}$ and $<10 \mathrm{~cm}$ : 3 years Patients with $B E$ with a maximum extent $\geq 10 \mathrm{~cm}$ should be referred for surveillance endoscopies to a BE expert center.

If a patient has reached 75 years of age at the time of his/ her last surveillance endoscopy and has no previous evidence of dysplasia, no subsequent surveillance endoscopies should be performed.

- Disagreement between merged guidelines

- New evidence available on this statement

- Consensus on current statement between Working Group members

\section{Comments}

The extent of BE is an accepted risk factor for malignant progression [8]. The suggested cutoff levels are arbitrary.

The cutoff of $10 \mathrm{~cm}$ for referral to a BE expert center is based on the finding that the risk for progression in these patients might reach a level comparable to that of patients with a confirmed diagnosis of low grade dysplasia (LGD) (see Statement 12 below) for which referral to an expert center is also advised (see Statement 17 below).

The age cutoff is also arbitrary, and is based on average life expectancy; hence, surveillance extension up to 80 years can be considered in individual cases.

Contrary to earlier guidelines, the Working Group does not recommend a standard follow-up endoscopy at 1 year after the first diagnosis of $\mathrm{BE}$, provided that the initial (diagnostic) endoscopy is performed according to the standards as described in this Position Statement (e.g. high definition endoscopy, adequate setting, sufficient number of random biopsies).

\section{STATEMENT 8}

Prophylactic endoscopic therapy (such as ablation therapy) for non-neoplastic BE should not be performed.

- Disagreement between merged guidelines

- No new evidence available on this statement

- Consensus on current statement between Working Group members

\section{Comments}

The average risk of cancer progression in patients with nondysplastic BE is low, estimated at about $0.3 \%$ per year [1]. This leads to a high number-needed-to-treat for the prevention of a single case of cancer, and consequently to unfavorable cost-effectiveness. In addition, uncertainty exists on the need for longterm follow-up in patients with nondysplastic BE post ablation.

\section{STATEMENT 9}

The diagnosis of any degree of dysplasia (including "indefinite for dysplasia") in BE requires confirmation by an expert Gl pathologist.

- Agreement between merged guidelines

- New evidence available on this statement

- Consensus on current statement between Working Group members

\section{Comments}

An accepted definition of the term "expert GI pathologist" is lacking. The Working Group suggests the following description: "an expert GI pathologist is a pathologist with special interest in Gl pathology recognized as such by his/her peers." When considering endoscopic treatment, confirmation by an independent pathologist from an independent institution is preferable in order to increase robustness of the diagnosis.

The addition of p53 immunostaining to the histopathological assessment may improve the diagnostic reproducibility of a diagnosis of dysplasia in BE and should be considered as an adjunct to routine clinical diagnosis.

The importance of expert histopathology review is underscored by studies showing that the majority of patients with a community diagnosis of LGD are downstaged to nondysplastic BE by expert Gl pathologists. In patients with confirmed LGD, however, progression rates to high grade dysplasia (HGD) and cancer are considerable $[9,10]$. 


\section{STATEMENT 10}

Patients with a diagnosis of "indefinite for dysplasia" confirmed by a second expert GI pathologist should be managed with optimization of antireflux medication and repeat endoscopy at 6 months. If no definite dysplasia is found in subsequent biopsy samples (including if the biopsies are again classified as "indefinite for dysplasia”), then the surveillance strategy should follow the recommendation for nondysplastic BE.

- Recommendation only present in one guideline

- No new evidence available on this statement

- Consensus on current statement between Working Group members

\section{STATEMENT 11}

Patients with visible lesions in BE diagnosed as dysplasia or early cancer should be referred to a BE expert center. All visible abnormalities, regardless of the degree of dysplasia, should be removed by means of endoscopic resection techniques in order to obtain optimal histopathological staging.

- Agreement between merged guidelines

- New evidence available on this statement

- Consensus on current statement between Working Group members

\section{Comments}

For Barrett's lesions containing dysplasia or early cancer, endoscopic submucosal dissection (ESD) and endoscopic mucosal resection (EMR) are both highly effective. ESD was not shown to provide improved overall patient outcome compared with EMR, yet it is considered to be technically more difficult and is associated with a higher rate of complications [11,12]. Therefore, EMR is the preferred resection technique for early Barrett's neoplasia. ESD may be indicated for removal of lesions with a significant luminal component ("bulky lesions") that cannot be removed by cap-based techniques, and for lesions where submucosal invasion is suspected.

\section{STATEMENT 12}

Patients with LGD on random biopsies confirmed by a second expert $\mathrm{GI}$ pathologist should be referred to a $\mathrm{BE}$ expert center. A surveillance interval of 6 months after confirmed LGD diagnosis is recommended.

i. If no dysplasia is found at the 6-month endoscopy, the interval can be broadened to 1 year. After two subsequent endoscopies negative for dysplasia, standard surveillance for patients with nondysplastic $B E$ can be initiated.

ii. If a confirmed diagnosis of LGD is found in the subsequent endoscopies, endoscopic ablation should be offered.

- Partial agreement between merged guidelines

- New evidence available on this statement

- Consensus on current statement between Working Group members

\section{Comments}

In $30 \%$ of patients with a single endoscopy diagnosis of confirmed LGD, the diagnosis will not be reproduced on subsequent endoscopies [9]. A single diagnosis of confirmed LGD therefore does not justify endoscopic ablation therapy.

Confirmed LGD, especially if it is repeated over time, and/or if it is documented at multiple esophageal levels, is a strong risk factor for progression to HGD and EAC [10].

Based on the currently available literature, radiofrequency ablation (RFA) has the best efficacy and safety profile, hence it is recommended as the technique of choice for ablation of $\mathrm{BE}$ [13].

\section{STATEMENT 13}

Patients with HGD confirmed by a second expert GI pathologist should be referred to a BE expert center. In the expert center, a high-definition endoscopy should be repeated according to the following guidelines.

i. All visible abnormalities should be removed by endoscopic resection techniques for adequate histopathological staging.

ii. If no lesions suspicious for dysplasia are seen, random 4-quadrant biopsies should be taken; if these biopsies are negative for dysplasia, endoscopy should be repeated at 3 months. If these biopsies confirm the presence of HGD, endoscopic ablation is recommended, preferably with RFA.

- Partial agreement between merged guidelines

- No new evidence available on this statement

- Consensus on current statement between Working Group members 


\section{Comments}

True flat HGD without endoscopically visible lesions is rare and accounts for less than $20 \%$ of patients with HGD. The absence of visible abnormalities in a patient with HGD is most often the result of an overlooked lesion, or over-staging of the histopathology. Flat HGD (as for flat LGD) therefore requires a confirmed diagnosis on two separate time points before treatment is initiated.

\section{STATEMENT 14}

Endoscopic resection is the first-choice therapy for T1a EAC.

- Agreement between merged guidelines

- No new evidence available on this statement

- Consensus on current statement between Working Group members

\section{Comment}

A diagnosis of esophageal adenocarcinoma is virtually always associated with an endoscopically visible abnormality, which requires endoscopic resection for staging and treatment.

In the absence of a visible lesion, a diagnosis of esophageal adenocarcinoma should be followed by a second imaging endoscopy to find the area of interest instead of performing ablation therapy for flat "invisible" cancer.

\section{STATEMENT 15}

In patients with T1b EAC, the optimal treatment strategy depends on histopathological characteristics of the endoscopic resection specimen. Endoscopic resection may be a valid alternative to surgery and is recommended in patients who are borderline fit for surgery, if the endoscopic resection specimen meets all of the following criteria:

i. submucosal invasion limited to $<500 \mu \mathrm{m}$;

ii. tumor differentiation grade: well or moderate;

iii. absence of tumor invasion in lymphatic vessels or blood vessels;

iv. absence of tumor infiltration in the deep resection margin.

- Partial agreement between merged guidelines

- New evidence available on this statement

- Consensus on current statement between Working Group members

\section{Comments}

The choice between endoscopic therapy and surgical resection should be based on a careful assessment of the risk of lymph node metastasis, surgical mortality and morbidity, and patient preferences. Tumors fulfilling all of the abovementioned criteria are considered as low-risk T1b cancers; the risk of lymph node metastasis appears to be low (<2\%) [14].

\section{STATEMENT 16}

After endoscopic resection of visible abnormalities containing any degree of dysplasia or neoplasia, complete eradication of all remaining Barrett's epithelium should be strived for, preferably with RFA.

- Partial agreement between merged guidelines

- No new evidence available on this statement

- Consensus on current statement between Working Group members

\section{Comment}

After endoscopic resection of visible abnormalities, recurrence rates between $15 \%$ in 5 years and $30 \%$ in 3 years have been reported for patients in whom the remaining BE is left untreated.

\section{STATEMENT 17}

All patients with a $B E \geq 10 \mathrm{~cm}$, a confirmed diagnosis of LGD, HGD, or early cancer should be referred to a BE expert center for surveillance and/or treatment.

A BE expert center should meet the following requirements.

i. Annual case load of $\geq 10$ NEW patients with endoscopic treatment for HGD or early carcinoma per BE expert endoscopist.

ii. Endoscopic and histological care is provided by endoscopists and pathologists who have followed additional training in this field (either by courses or guest visits). A minimum of 30 supervised cases of endoscopic resection and 30 cases of endoscopic ablation should be performed to acquire competence in technical skills, management pathways, and complications.

iii. Patients with Barrett's neoplasia are discussed in multidisciplinary meetings with gastroenterologists, surgeons, oncologists, and pathologists.

iv. Access to experienced esophageal surgery.

v. All patients with BE are registered prospectively in a database.

- Partial agreement between merged guidelines

- No new evidence available on this statement

- Consensus on current statement between Working Group members 
ESGE position statements represent a consensus of best practice based on the available evidence at the time of preparation. They may not apply in all situations and should be interpreted in the light of specific clinical situations and resource availability. Further controlled clinical studies may be needed to clarify aspects of these statements, and revision may be necessary as new data appear. Clinical consideration may justify a course of action at variance to these statements. ESGE position statements are intended to be an educational device to provide information that may assist endoscopists in providing care to patients. They are not rules and should not be construed as establishing a legal standard of care or as encouraging, advocating, requiring, or discouraging any particular treatment.

\section{Acknowledgment}

The working group thank Prof. H. Messmann for his valuable comments on the manuscript.

\section{Competing interests}

R. Bisschops has received: speaker's fees from Covidien (20092014) and Fujifilm (2013); speaker's fee and hands-on training sponsorship from Olympus Europe (2013 - 2014); speaker's fee and research support from Pentax Europe; and an editorial fee from Thieme Verlag as co-editor of Endoscopy. E. Coron has provided paid consultancies to Mauna Kea Technologies (2011-2015), Fujifilm (2016-), and Medtronic (2015-); his department has received training sessions in ESD from Fujifilm (2014-2016). M. di Pietro has received sponsorship for educational events (2015-2016). B. Weusten's department has received research support for IRB-approved studies from C2 Therapeutics (2012-), Boston Scientific (2015-), and Medtronic (2013-). M. Dinis-Ribeiro, J.-M. Dumonceau, J.-M. Esteban, C. Hassan, O. Pech, and A. Repici have no competing interests.

\section{References}

[1] Desai TK, Krishnan K, Samala N et al. The incidence of oesophageal adenocarcinoma in non-dysplastic Barrett's oesophagus: a metaanalysis. Gut 2012; 61: $970-976$
[2] Dumonceau J-M, Hassan C, Riphaus A, Ponchon T. European Society of Gastrointestinal Endoscopy (ESGE) guideline development policy. Endoscopy 2012; 44: 626-629

[3] Verbeek RE, Leenders M, Ten Kate FJW et al. Surveillance of Barrett's esophagus and mortality from esophageal adenocarcinoma: a population-based cohort study. Am J Gastroenterol 2014; 109: 1215 1222

[4] Kastelein F, van Olphen SH, Steyerberg EW et al. Impact of surveillance for Barrett's oesophagus on tumour stage and survival of patients with neoplastic progression. Gut 2016; 65: 548- 554

[5] Fitzgerald RC, di Pietro M, Ragunath K et al. British Society of Gastroenterology (BSG) guidelines on the diagnosis and management of Barrett's oesophagus. Gut 2014; 63: 7-42 Available from: http:// gut.bmj.com/content/63/1/7.full.pdf+html

[6] Koop H, Fuchs KH, Labenz J et al. (\$2k Guideline: Gastroesophageal Reflux Disease Guided by the German Society of Gastroenterology AWMF Register No. 021-013). Z Gastroenterol 2014; 52: 1299-1346 Available from: https://www.thieme-connect.com/products/ejournals/pdf/10.1055/s-0034-1385202.pdf

[7] Sharma P, Bergman J], Goda K et al. Development and validation of a classification system to identify high-grade dysplasia and esophageal adenocarcinoma in Barrett's esophagus using narrow-band imaging. Gastroenterology 2016; 150: 591 - 598

[8] Pohl H, Pech O, Arash H et al. Length of Barrett's oesophagus and cancer risk: implications from a large sample of patients with early oesophageal adenocarcinoma. Gut 2016; 65: 196-201

[9] Phoa KN, van Vilsteren FGI, Weusten BLAM et al. Radiofrequency ablation vs endoscopic surveillance for patients with Barrett esophagus and low-grade dysplasia. JAMA 2014; 311: 1209-1217

[10] Duits LC, Phoa KN, Curvers WL et al. Barrett's oesophagus patients with low-grade dysplasia can be accurately risk-stratified after histological review by an expert pathology panel. Gut 2015; 64: 700 - 706

[11] Pimentel-Nunes P, Dinis-Ribeiro M, Ponchon T et al. Endoscopic submucosal dissection: European Society of Gastrointestinal Endoscopy (ESGE) guideline. Endoscopy 2015; 47: 829-854

[12] Terheggen G, Horn EM, Vieth M et al. A randomised trial of endoscopic submucosal dissection versus endoscopic mucosal resection for early Barrett's neoplasia. Gut 2016: 1-11 Available from: http:// gut.bmj.com/lookup/doi/10.1136/gutjnl-2015-310126

[13] Small AJ, Araujo JL, Leggett CL et al. Radiofrequency ablation is associated with decreased neoplastic progression in patients with Barrett's esophagus and confirmed low-grade dysplasia. Gastroenterology 2015; 149: 567 - 576.e3

[14] Manner H, Pech O, Heldmann Y et al. The frequency of lymph node metastasis in early-stage adenocarcinoma of the esophagus with incipient submucosal invasion (pT1b sm1) depending on histological risk patterns. Surg Endosc 2015; 29: 1888-1896 